\title{
Stress state along the Anninghe-Zemuhe fault zone, southwestern China, estimated from an array of stress orientation measurements with a new method
}

\author{
Yasuto Kuwahara ${ }^{1}$, Tsutomu Kiguchi ${ }^{1}$, Xinglin $\mathrm{Lei}^{1}$, Shengli Ma ${ }^{2}$, Xueze Wen ${ }^{3}$, and Shunyun Chen ${ }^{2}$ \\ ${ }^{1}$ Geological Survey of Japan, AIST, Japan \\ ${ }^{2}$ State Key Laboratory of Earthquake Dynamics, Institute of Geology, China Earthquake Administration, China \\ ${ }^{3}$ Earthquake Administration of Sichuan Province, China
}

(Received July 23, 2010; Revised August 18, 2011; Accepted August 22, 2011; Online published March 2, 2012)

\begin{abstract}
Measurements of in-situ stress orientations at relatively shallow depths were conducted at 11 sites along the Anninghe-Zemuhe fault zone, southwestern China, with a newly developed method. The Anninghe fault in the fault zone has been considered to have a potential for a large earthquake with a magnitude of about 7.5, while the Zemuhe fault shows very little such potential. The present study has mainly two objectives: one is to show new data of the spatial distribution of the stress orientations around the fault zone, which is obtained directly from the measurements; the other is to examine the possibility to detect a stress pattern in relation to the past activities of earthquakes along the fault zone. The observed principal stress orientations are distributed between the NNWSSE and NW-SE directions, which is consistent with the earthquake focal mechanism solutions near the fault zone. On the other hand, it is unclear whether the observed stress pattern is related to past activities of the fault zone, since the data uctuation was too large to determine this. We note that the stress orientations are favorable for slip on the Anninghe fault, while being unfavorable on the Zemuhe fault, from the present experimental data. Key words: The Anninghe-Zemuhe fault zone, in-situ stress measurements, new technique, laser displacement sensor, active fault, earthquake forecasts.
\end{abstract}

\section{Introduction}

The Anninghe-Zemuhe fault zone, southwestern China, is a highly active left-lateral strike-slip fault system with a length of about $200 \mathrm{~km}$ (Fig. 1). The fault zone is located in the eastern margin area of the Tibetan plateau, and is a portion of a larger fault system forming the eastern edge of the Sichuan-Yunnan active tectonic block. The slip rate along this large fault zone is determined to be up to 6$7 \mathrm{~mm} / \mathrm{yr}$ from geological studies (Wen et al., 1988). Strikes of the Anninghe and the Zemuhe faults are trending N-S and $\mathrm{N} 30^{\circ} \mathrm{W}$, respectively. Seismic activity which has occurred along this fault zone after AD1300 has been extensively studied, so that the Anninghe fault is recognized as a seismic gap having a high potential of an earthquake of magnitude $(M) 7.4$, while the Zemuhe fault was ruptured by an $M 7.5$ earthquake in 1850 , only 160 years ago (Wen et al., 2008). Thus, comprehensive studies on the Anninghe fault are expected to consider various aspects, such as stress states and the seismicity of micro-earthquakes (e.g. Yang, Z.-X. et al., 2005; Wen et al., 2008), crustal movement (e.g. Yang, S.-M. et al., 2005) and so on, leading to more precise forecasts of future earthquakes.

Recent observations of stress states on other faults after large earthquakes fall into two viewpoints: one is that stress

Copyright (c) The Society of Geomagnetism and Earth, Planetary and Space Sciences (SGEPSS); The Seismological Society of Japan; The Volcanological Society of Japan; The Geodetic Society of Japan; The Japanese Society for Planetary Sciences; TERRAPUB.

doi:10.5047/eps.2011.08.017 states are little affected by the main shock, which suggests that the stress drop of the main shock, relative to the tectonic stress level, is small (e.g. Kubo and Fukuyama, 2004). The other is the opposite case, suggesting that the stress drop of the main shock is comparable to the tectonic stress level (e.g. Hardebeck and Hauksson, 2001; Yamashita et al., 2004). If the conclusion of a relatively small stress drop is the case, then a stress measurement might not be directly useful for earthquake forecasts, because the measurement would not be able to resolve stress variations during an earthquake cycle. On the other hand, in the opposite case, stress measurements would be quite valuable for earthquake forecasts, because the stress accumulation process on the fault is likely to be observed by stress measurements. Considering these two con icting observations, it is necessary to examine two aspects of the stress state of the Anninghe-Zemuhe fault zone: the rst is whether the stress drop on the Zemuhe fault, relative to the tectonic stress at the latest earthquake in 1850 , is detectable or not. The second is to determine what the stress state on the Anninghe fault is, relative to the tectonic stress.

The stress state around the two faults might be indicated by the focal mechanism solutions of micro-earthquakes. While Cheng et al. (2006) have shown that the average azimuths of the $P$-axis of the focal mechanism solutions are ESE-WNW over a relatively large regional area including the Anninghe fault, and NW-SE in an regional area including the Zemuhe fault, they do not estimate the local stress eld near the two faults. The data of the azimuth of the $P$ - 


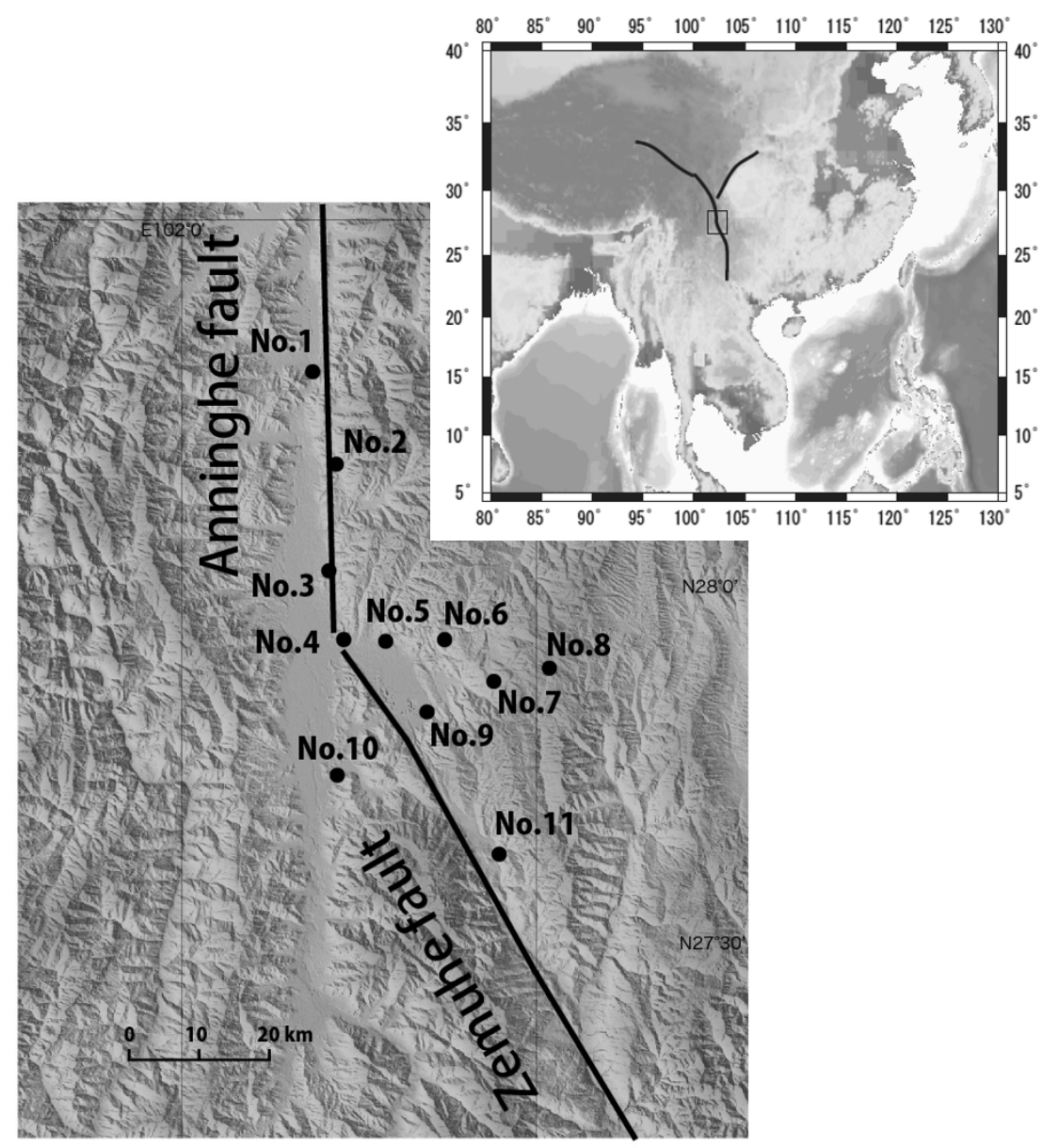

Fig. 1. Location of the Anninghe-Zemuhe fault zone and the sites for stress-orientation measurements. The two bold lines in the left panel denote the Anninghe and the Zemuhe faults. Black dots indicating No. 1-No. 11 show the site locations for the measurements.

axis seem to be rather scattered in gure 1 of Cheng et al. (2006), so that it is dif cult to clarify the local stress elds along the two faults from this data. Cui et al. (2006) and Huang et al. (2009) present data concerning earthquake focal mechanisms of $M>4$, and in-situ stress measurements with a stress relief method, or a hydraulic fracturing one, at several different sites along the Anninghe-Zemuhe fault zone. They show that the orientation of the maximum horizontal stress is roughly in the NW-SE direction. The data are, however, insuf cient to depict a high-resolution stress eld related to the difference of activities of the Anninghe and the Zemuhe faults. More data are thus necessary to clarify the stress state along the fault zone.

Usual stress-measurement techniques, such as stress relief and hydraulic fracturing experiments, are generally difcult to perform at many sites due to the high costs of the measurements. Kuwahara and Kiguchi (2006), Kiguchi and Kuwahara (2006) and Kiguchi et al. (2010) have recently developed a new relatively low cost method for measuring crustal stress orientations in Japan. The principle of the new method is to measure directly the creep deformation of the borehole just after drilling into bedrock under some crustal stress. An advantage of the new method is that it involves easier technical procedures at a relatively lower cost, leading to the possibility of many measurements in different locations. One disadvantage of this method is that it can pro- vide only data relating to the orientation of the horizontal maximum principal stress, $S_{H \max }$, at shallow depths down to about $20 \mathrm{~m}$. On the other hand, Sbar et al. (1984) and Plumb et al. (1984) have shown that the majority of stress orientation data obtained at shallow depths of less than about $20 \mathrm{~m}$ are consistent with data at deeper depths, say, contemporary tectonic stresses. They also pointed out that the disturbance caused by thermally-induced stress from the surface is negligibly small at depths deeper than $10 \mathrm{~m}$. We expect, therefore, to obtain an abundance of meaningful data to estimate the tectonic stress led, with this new method. In the following section, we will discuss the effectiveness of only stress orientation data, without absolute values of stresses, for estimating the stress state of faults.

Based on the above, an opportunity has arisen for cooperation between China and Japan to measure stress elds at 11 sites along the Anninghe-Zemuhe fault zone. The present paper describes the procedures of site selections and measurements. The effect of the actual landscape topography on the measured data is also discussed. We then compare the $S_{H \text { max }}$ orientations measured applying the new method with theoretical stress elds calculated assuming various stress states, on both faults, related to the past activity of each fault, in order to examine the differences. 


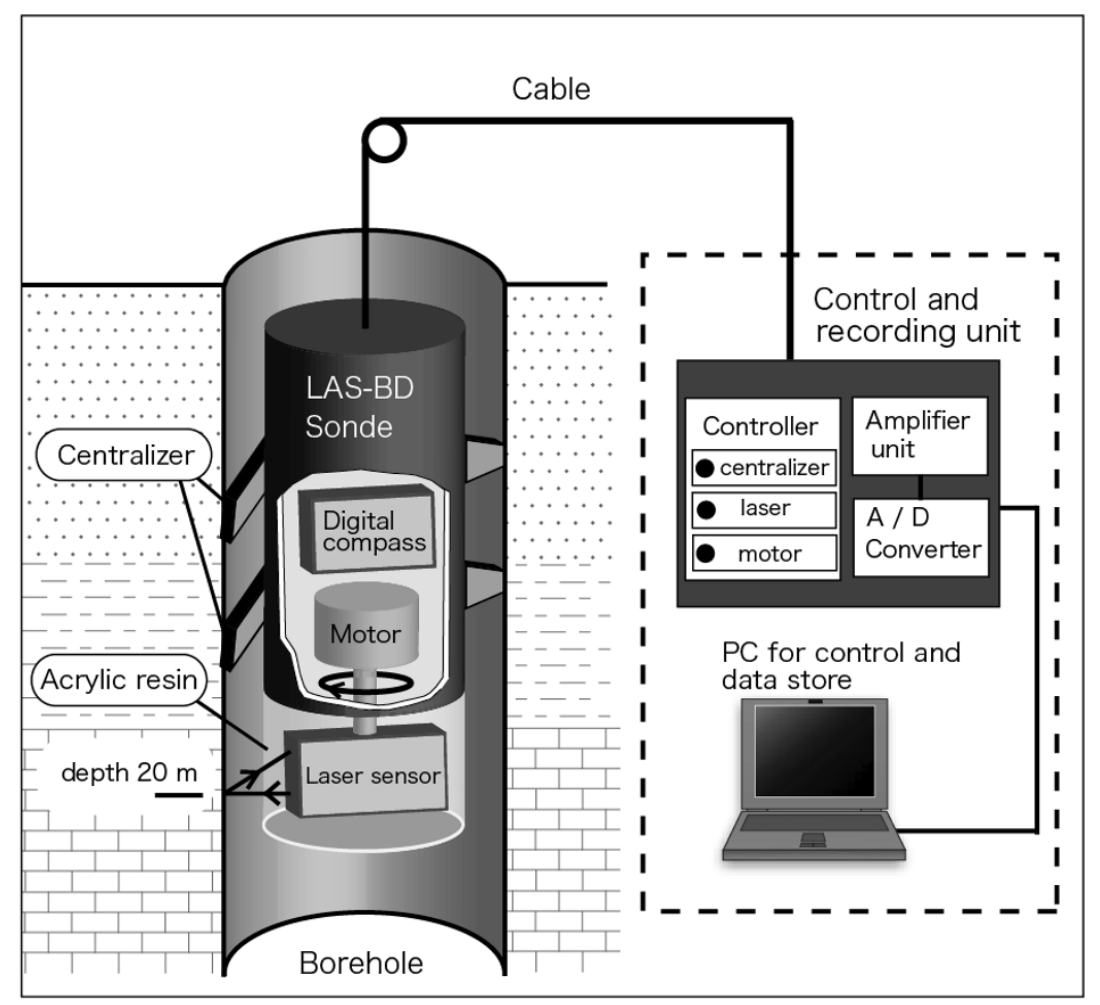

Fig. 2. Schematic diagram of a new tool for stress-orientation measurements.

\section{Experiment}

\subsection{New method}

We brie y describe here the new method used for measuring the stress orientation at shallow depths in the present study, following Kiguchi et al. (2010). The new method is based on the following principles: (1) A borehole drilled in stressed bedrock is expected to be quasi-statically deformed due to the viscous property of the rock just after drilling. (2) The orientation of $S_{H \max }$ coincides with the orientation of the minor axis of an ellipse tted to the relative change of shape of the borehole cross-section during the deformation. The main advantage of this method is the notably lower cost to estimate the stress orientation, compared with existing methods, such as stress relief and hydraulic fracturing methods. One might expect that an absolute value of the crustal stress could be determined, if the viscosity of the rock could be measured. However, it is dif cult to estimate the absolute value, since the measurement of viscosity is dif cult under the low stress condition of this method corresponding to the shallow depth.

A downhole tool for measuring the borehole deformation has been newly developed by Kuwahara and Kiguchi (2006) and Kiguchi et al. (2010), too. The tool is mainly composed of a laser sensor with a rotary mechanism, a digital compass with tilt meters for a tool direction measurement and centralizers (Fig. 2). The tilt meters are also monitored to check the xation stability of the downhole tool, in the borehole, during a measurement. The laser displacement sensor located at the bottom of the tool is continuously rotated $360^{\circ}$ to measure the radial displacement of the borehole wall under creep deformation, just after drilling. Two centralizers are collocated to $\mathrm{x}$ the tool in the borehole during a mea- surement. The tool is designed to be used in a borehole of $116 \mathrm{~mm}$, or $123 \mathrm{~mm}$, diameter. These sizes are adopted, taking into consideration the focus distance, size of laser displacement sensor, and Japanese standards of borehole diameters. The raw data from the laser sensor are transferred to the $\mathrm{PC}$ on the ground surface at a sampling rate of $5 \mathrm{kHz}$. A radial distance of the borehole at each $2^{\circ}$ in rotation is obtained by averaging the 7500 raw data covering a range of $1.5^{\circ}$ around the each $2^{\circ}$. It takes 6 minutes to rotate the laser sensor one complete rotation (one lap). After several operation tests in the laboratory, the total resolution of the tool is estimated to be about $0.7 \mu \mathrm{m}$, which is enough to measure the expected deformation for the typical rock and stress conditions at a shallow depth (Kiguchi et al., 2010).

\subsection{Selection of site locations}

Site locations for the measurements were mainly determined from theoretical and technical considerations to effectively evaluate the difference between the stress states of the Anninghe and the Zemuhe faults. From the theoretical point of view, the difference between the stress states on the two faults can be assumed to be large enough to be evaluated in the case of a large relative stress drop occurring during the latest main shock, because the elapsed times since the latest large earthquakes on each fault are signi cantly different, as mentioned. We thus calculate stress elds theoretically, assuming a simple model where the stress on the fault, comparing the background tectonic stress, varies with elapsed time as follows: The shear stress on the fault becomes low comparing the background stress just after the earthquake, and gradually increases to a background stress level. If such is the case, the stress concentrations at the edges of the fault should be relaxed with the 
(a)

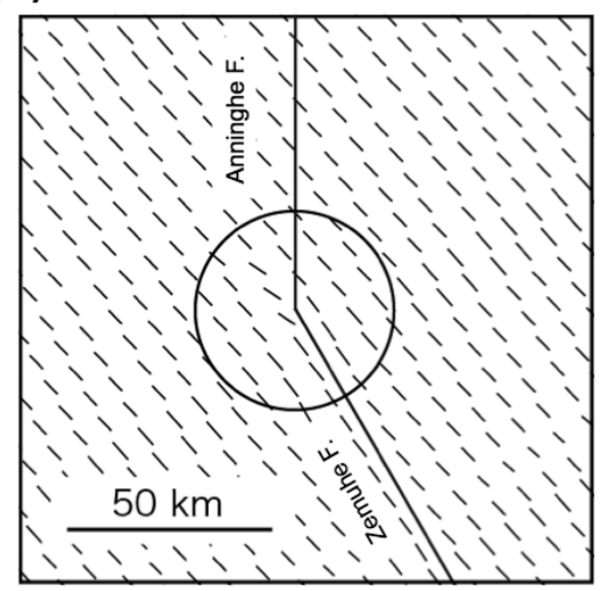

(b)

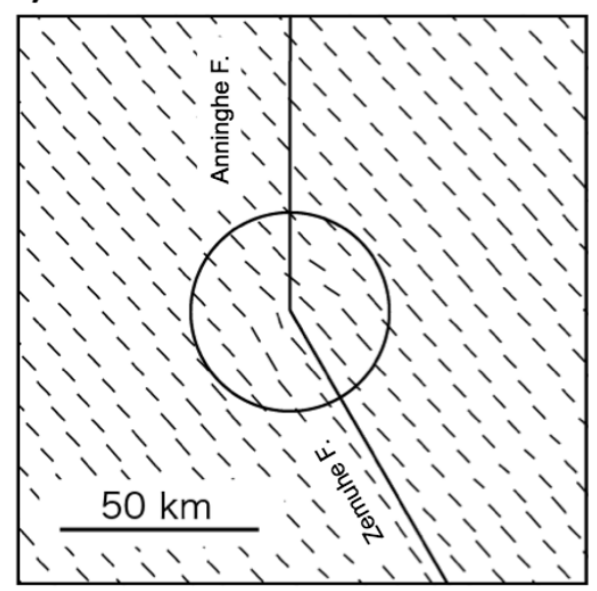

Fig. 3. Theoretical orientations of maximum principal stresses. The background stress is assumed to be uniform with the direction N45 ${ }^{\circ}$. Stress on the Anninghe fault is (a) 100\% and (b) $30 \%$ of the background stress, respectively, while the stress on the Zemuhe fault is $0 \%$ of the background stress. A large difference of the stress orientations between the two models can be observed in the bold circle area with a diameter of $50 \mathrm{~km}$.

passage of time, probably due to the inelastic property of the upper crust. Figures 3(a) and (b) show examples of the distribution of the maximum principal stress $\left(S_{H \max }\right)$ orientation where the stresses on the Anninghe fault are (a) $100 \%$ and (b) $30 \%$ of the background tectonic stress, respectively, while the stress on the Zemuhe fault is $0 \%$ of the background stress both for Figs. 3(a) and (b). The cases in Figs. 3(a) and (b) correspond to the conditions of entirely recovered stress, and 30\% recovered stress, respectively, on the Anninghe fault from the latest earthquake on the Anninghe fault, while the stress drop of the Zemuhe fault at the last earthquake in 1850 is $100 \%$ relative to the tectonic stress without postseismic stress recovery. Many distributed short lines in Fig. 3 denote the orientations of $S_{H \max }$ at a spacing of $7.5 \mathrm{~km}$. The calculations were performed by the software, Coulomb, developed by Toda et al. (1998). The background stress is assumed to be uniform with an $S_{H \max }$ orientation of $\mathrm{N}^{\circ} 5^{\circ} \mathrm{W}$, which is estimated from seismological observations (e.g. Cheng et al., 2006). The amount of left-lateral slip, equivalent to the stress drop on the fault, is obtained by using the relation, $\Delta \tau=C \mu U / W$, where $U$ is the average slip on the fault, $W$ is a fault width, $C$ is a non-dimensional constant depending on the shape of the fault and slip direction, and $\mu$ is the shear modulus. Here, we use $C=\pi / 2$ for the strike slip fault intersecting the Earth's surface (Knopoff, 1958; Aki, 1972), $W=20 \mathrm{~km}$, and $\mu=3.2 \times 10^{10} \mathrm{~Pa}$. Although this assumption may be a rather simpli ed case, the characteristics of an actual stress pattern might not be much different from the calculation based on this assumption. It is seen from Fig. 3 that the stress state on the fault, relative to the tectonic stress, can be effectively estimated only at the vicinity of the junction of the Annignhe and the Zemuhe faults. Thus, we roughly choose sites where a large difference in the stress orientations between the two models of Figs. 3(a) and (b) can be observed in the theoretical results, as indicated by bold circles with a radius of $25 \mathrm{~km}$. It should be noted that a disturbance of the stress orientations in the vicinity of the junction of the two faults becomes small for the case of the small relative stress drop of the 1850 Zemuhe-fault earthquake.

The technical reasons for choosing the sites mainly relate to the hardness of the rock and the landscape topography. To some extent, the rock should be hard, because stress cannot accumulate in soft rocks due to their ductility. We generally use the criterion of a $P$ wave velocity in rock of larger than about $3 \mathrm{~km} / \mathrm{s}$ as an index of hard rock (Sato et al., 2004). Regarding the landscape topography, a at, or gently sloping, landscape topography is generally better for measurements, since steep slope topography especially affects the shallow stress (e.g. Liu and Zoback, 1992). Therefore, we avoid measuring near a steep slope. We will later show that the topography effect on the shallow stress state is not dominant, by carrying out a computer simulation of a nite element modeling for the actual topography of a site in the present experiment.

We nally chose the 11 sites shown in Fig. 1 from the gentle-sloping topography sites from all the candidates, taking into consideration the above points. Each site is a different distance from the faults, or from the edge of the faults along the strike.

\subsection{Measurements}

We conducted up to three measurements at different depths ranging from $10 \mathrm{~m}$ to $18 \mathrm{~m}$ for a given site. Drilling and measurements for a given site were basically carried out as follows: we rst drilled a borehole down to $10 \mathrm{~m}$ or more to check the condition of the borehole rock by judging from the core samples about the hardness and smallness of the fracture density. If the condition was good enough to measure, a measurement of the stress orientation was made at that depth for 2 to 3 hours. We then retrieved the downhole tool and drilled at least $50 \mathrm{~cm}$ deeper. We then repeated the core samples check and measured the deformation again. Although a measurement time of a few hours was usually enough to estimate the stress orientation, we took measurements all night, because drilling work was impossible during the night-time. Thus, measurement times were about 2 
Table 1. Summary of site parameters and the measurement results.

\begin{tabular}{|c|c|c|c|c|c|c|c|}
\hline Loc. & $\begin{array}{l}\text { Latitude } \\
\left({ }^{\circ} \mathrm{N}\right)\end{array}$ & $\begin{array}{l}\text { Longitude } \\
\left({ }^{\circ} \mathrm{E}\right)\end{array}$ & $\begin{array}{l}\text { Elevation } \\
\text { above sea } \\
\text { level }(\mathrm{m})\end{array}$ & $H(\mathrm{~m})$ & $\phi$ & $F(\%)$ & $\begin{array}{c}\text { Remark for } \\
\text { incomplete } \\
\text { measurements }\end{array}$ \\
\hline \multirow{2}{*}{ No. 1} & \multirow{2}{*}{28.28666} & \multirow{2}{*}{102.18071} & \multirow{2}{*}{1630} & 16.15 & $\mathrm{~N} 20.0 \mathrm{~W}$ & $1 / 78.8$ & \multirow{2}{*}{ - } \\
\hline & & & & 17.55 & $\mathrm{~N} 23.5 \mathrm{~W}$ & $1 / 104.2$ & \\
\hline No. 2 & 28.15631 & 102.21574 & 1830 & - & - & - & $\begin{array}{c}\text { Borehole } \\
\text { rocks were } \\
\text { extremely } \\
\text { fractured }\end{array}$ \\
\hline \multirow{3}{*}{ No. 3} & \multirow{3}{*}{28.00168} & \multirow{3}{*}{102.20464} & \multirow{3}{*}{1620} & 10.8 & N66.3E & $1 / 173.8$ & \multirow{3}{*}{-} \\
\hline & & & & 12.73 & N79.7W & $1 / 602.0$ & \\
\hline & & & & 14.35 & $\mathrm{~N} 50.2 \mathrm{~W}$ & $1 / 205.0$ & \\
\hline No. 4 & 27.90708 & 102.22665 & 1500 & - & - & - & $\begin{array}{c}\text { Borehole } \\
\text { diameter was } \\
\text { too much } \\
\text { enlarged }\end{array}$ \\
\hline No. 5 & 27.90467 & 102.28582 & 1600 & 11.7 & $\mathrm{~N} 27.1 \mathrm{~W}$ & $1 / 119.1$ & - \\
\hline \multirow{2}{*}{ No. 6} & \multirow{2}{*}{27.90765} & \multirow{2}{*}{102.37041} & \multirow{2}{*}{1990} & 11.02 & $\mathrm{~N} 5.0 \mathrm{~W}$ & $1 / 87.7$ & \multirow{2}{*}{ - } \\
\hline & & & & 11.68 & N65.5E & $1 / 230.2$ & \\
\hline \multirow{2}{*}{ No. 7} & \multirow{2}{*}{27.8497} & \multirow{2}{*}{102.43963} & \multirow{2}{*}{2550} & 15.21 & $\mathrm{~N} 8.3 \mathrm{~W}$ & $1 / 41.1$ & \multirow{2}{*}{-} \\
\hline & & & & 16.9 & N83.9E & $1 / 466.1$ & \\
\hline No. 8 & 27.86825 & 102.51637 & 3120 & 11.9 & N64.5W & $1 / 135.9$ & - \\
\hline No. 9 & 27.80652 & 102.34776 & 1550 & - & - & - & $\begin{array}{l}\text { Borehole } \\
\text { rocks were } \\
\text { extremely } \\
\text { fractured }\end{array}$ \\
\hline No. 10 & 27.71728 & 102.21996 & 1500 & 15.85 & N35.0W & $1 / 27.8$ & - \\
\hline No. 11 & 27.60646 & 102.44778 & 1920 & - & - & - & $\begin{array}{c}\text { Borehole } \\
\text { water was } \\
\text { muddy }\end{array}$ \\
\hline
\end{tabular}

$H$ : measurement depth, $\phi: S_{H \max }$ orientation, $F$ : Flattening parameter of the tted ellipse.

to 3 hours during daytime and about 11 to 14 hours at nighttime. It took four weeks to conduct the measurements at 11 sites, from March to April, 2007, by using 3 boring machines. The measurements were successful at 7 sites, while for some sites only one measurement was meaningful. We could not measure at 4 sites due to the bad conditions of the boreholes.

The discarding of some measurements resulted mainly for three reasons. The rst one was highly damaged rock in the borehole. We skipped sites of heavily damaged rock because it is disastrous if the downhole tool is trapped in the borehole. The second reason was a too enlarged borehole diameter. In some cases, it was impossible to measure the borehole deformation, because its diameter became larger than the maximum focus distance of the laser displacement sensor. This is probably due to the combined effect of the drilling technique and the rock properties. The nal reason was muddy water in the borehole-caused by borehole-wall rock dust in the water. The laser beam of the laser sensor cannot be transmitted in very muddy water. Consequently, we analyzed data from 7 sites. Table 1 summarizes the locations of the measurements, the measurement depths at each location, and the reasons for unsuccessful measurements.

We recovered core samples from almost whole drilling depths with a drilling bit having an outer diameter of $116 \mathrm{~mm}$. Measurement depths were determined by core inspections. Examples of photos of core samples at the measurement depths are shown in Fig. 4. The rock type at site No. 1 is gabbro, while all the other core samples are sandstones. It is noted that the diameters are not apparently uniform along the axis of the core samples. This indicates that the borehole diameters were also not uniform along the borehole axis so that acceptable measurements were impossible at some depths, as described in the previous paragraph.

The anisotropy of the viscous and elastic properties of rock are other factors which might affect the accuracy of stress measurements with the present method. However, the measurement of viscosity is dif cult at present, as mentioned earlier, so that a study of the anisotropy effect on the deformation measurements will be the subject of future work. We thus measured only the $P$-wave anisotropy of the core sample from site No. 7, at a depth of about $15 \mathrm{~m}$ for reference. We suppose that the anisotropy of all the other core samples are not much different from the sample measured here, because none of the core samples appear to have a dominant orientation of cracks and fabrics, from visual inspection. Figure 5 shows $P$-wave velocities measured for various horizontal directions of a core sample from site No. 7. The result shows that the anisotropy of the $P$-wave velocity of the sandstone is less than $3 \%$, with an average $P$-wave velocity of $3720 \mathrm{~m} / \mathrm{s}$. The speci c gravity (density) and porosity of the core sample, from site No. 7, are 2690 
(a)

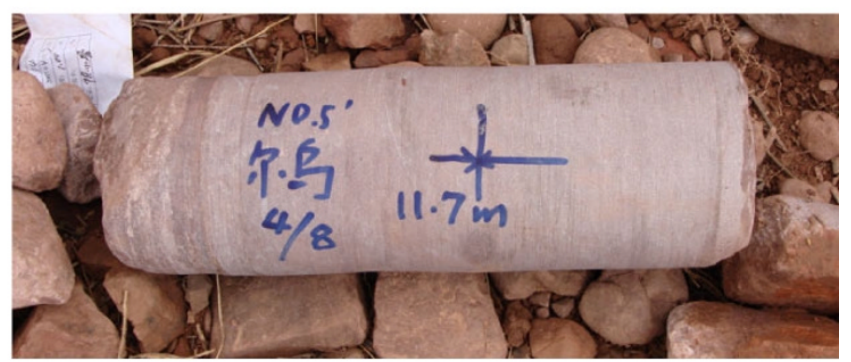

(b)

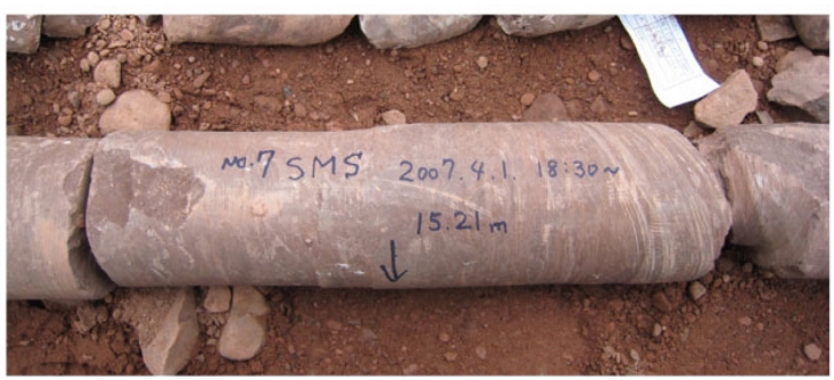

(c)

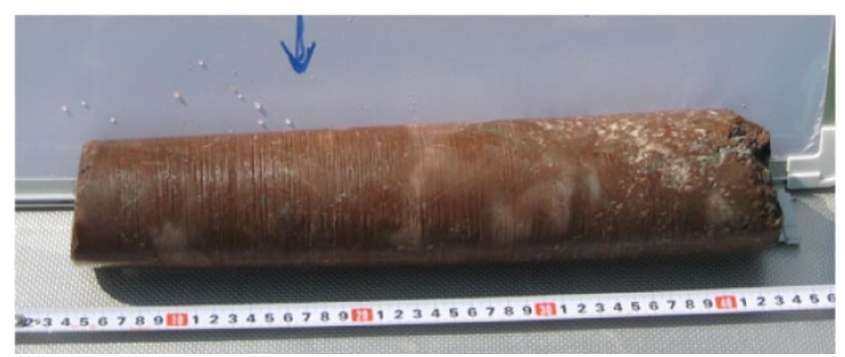

Fig. 4. Photos of core samples at various measuring depths. (a) for site No. 5, (b) for No. 7 and (c) for No. 10.

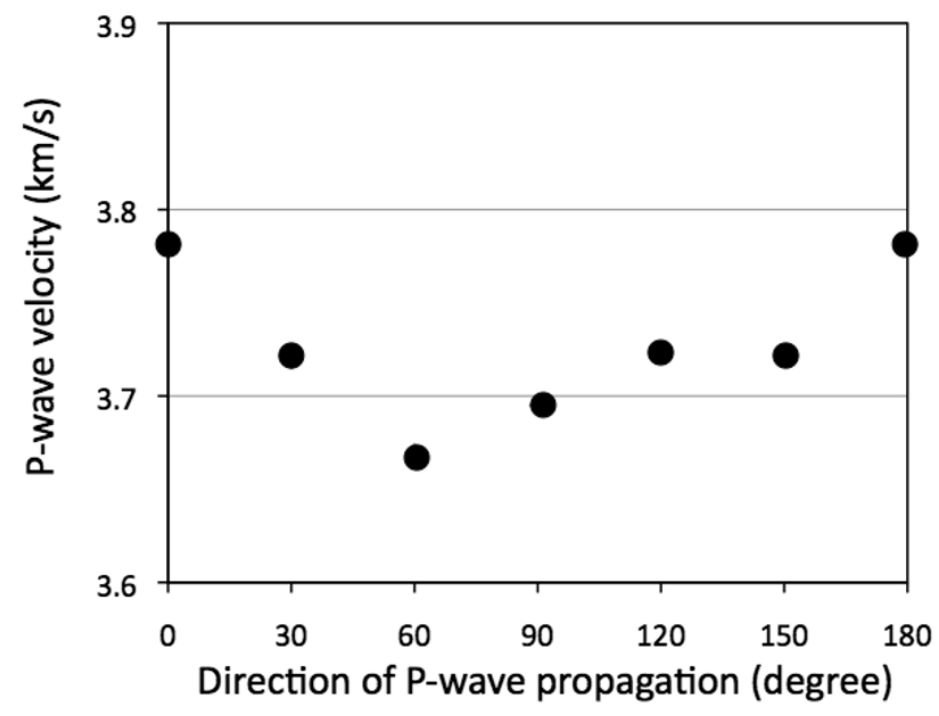

Fig. 5. $P$-wave velocities measured in various directions for the sample from site No. 7 . The absolute values of directions are relative to a reference direction, because core samples were not oriented. 


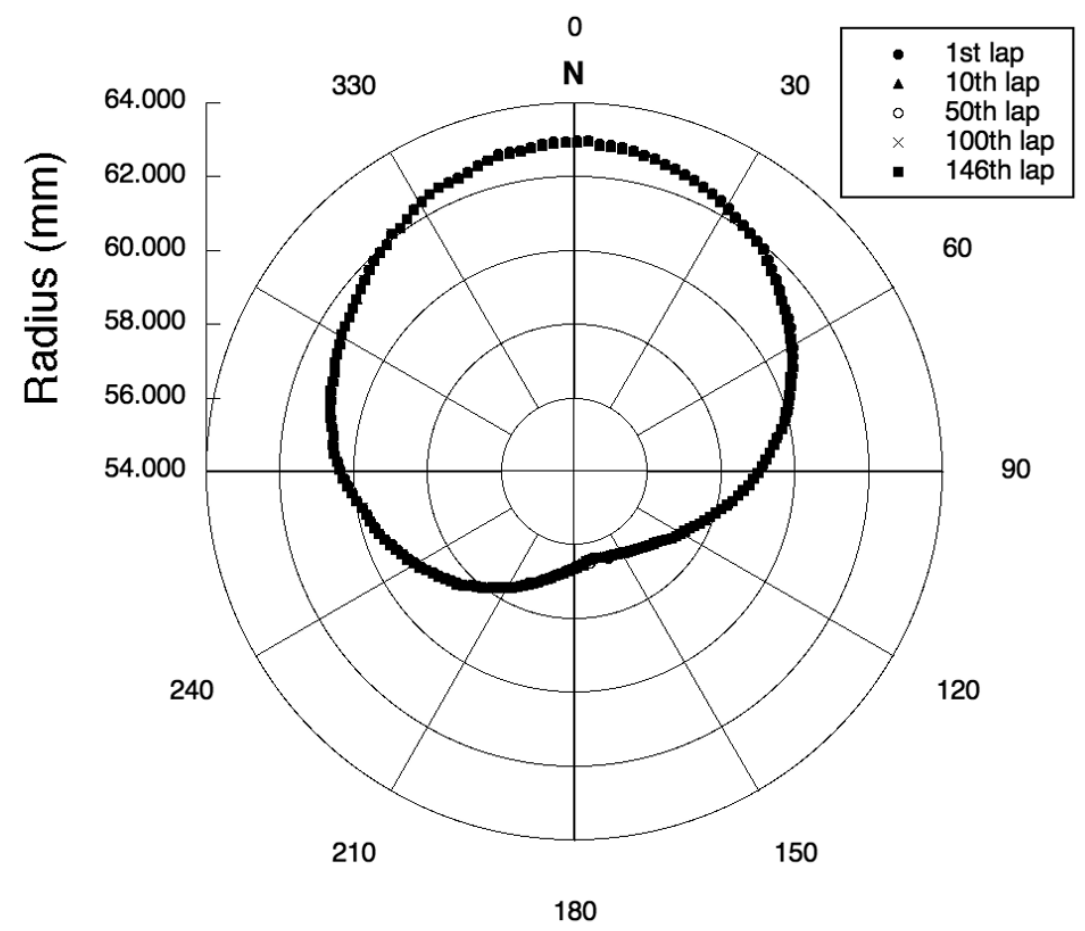

Fig. 6. An example of the original data of the borehole shape. All data for each lap are almost overlapped by the last 146th-lap data. This shows a good repeatability of the measurements in this resolution scale of the figure.

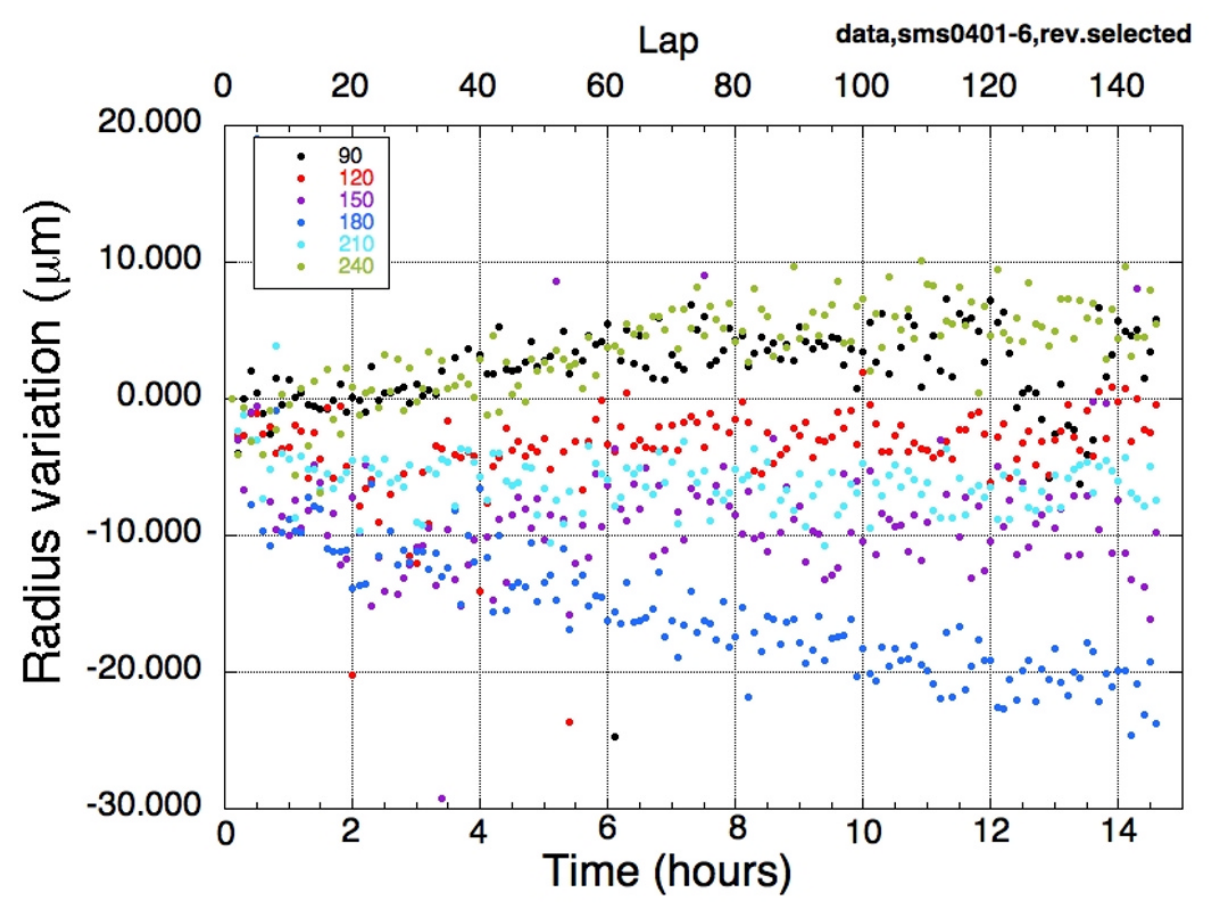

Fig. 7. Time variations of borehole diameters relative to the initial ones for the data of each orientation in Fig. 6 . In the inset box, "90" denotes the diameter for the direction $\mathrm{N} 90^{\circ} \mathrm{E}$, and so on.

$\mathrm{kg} / \mathrm{m}^{3}\left(2.69 \mathrm{~g} / \mathrm{cm}^{3}\right)$ and $4 \%$, respectively, at atmospheric pressure. It is also to be noted that the depths of measurements were chosen to be as far as possible from fractures, and more than $200 \mathrm{~mm}$ away from the bottom edges of the borehole, to avoid any stress disturbance from those effects. An example of original data from site No. 7 is shown in Fig. 6. Data with various symbols in the figure denote the distances from the center of the downhole tool to the borehole wall every 2 degrees of rotation for respective laps. Although the data of these respective laps are overlaid in the figure, all the data almost overlap at the same points in this scale of the figure. This indicates that the measurements 
are very stable. Distances at $170^{\circ}$ and at $350^{\circ}$ are about $56.5 \mathrm{~mm}$ and about $62.8 \mathrm{~mm}$, respectively. The downhole tool is considered, accordingly, to be decentered by about 3 $\mathrm{mm}$ in the borehole.

In Fig. 7, the time variations of borehole diameters relative to the initial ones, of the same data of Fig. 6, are depicted for some orientations, say $\mathrm{N} 90^{\circ} \mathrm{E}$ (hereafter $\mathrm{N} 90$, and similar expressions for others), N120, N150, N180, N210, and N240. Because the eccentricity of $3 \mathrm{~mm}$ of the downhole tool can be regarded as being negligibly small, the sum of both the point-symmetrical data in some orientation are approximately the diameter of the borehole for that orientation. We can detect continuous contraction and expansion in N180, and in N90 or N240, respectively, and relatively rapid deformation at an early stage. Although the data scatters are sometimes large, data errors seem to be generally a few $\mu \mathrm{m}$ in this gure. We thus believe that borehole deformation due to a viscous effect after drilling has been observed in the present experiment.

\section{Results}

Data processing for estimating the stress orientation is as follows: the relative change of the borehole shape during measurement was obtained from the difference between the borehole radii of the initial, and the nal, parts of the measurement. The borehole radius just after drilling, and that of the nal, part of the measurement were determined from the averaged data of the rst 5 laps and of the last 10 laps, respectively. We used a smaller number of averaging data for the rst part than for the last part, because the deformation rate in the rst part is larger than in the last part. Then, we analyzed to $t$ an ellipse to the relative change of the borehole shape by least-square tting. The unknown parameters for the tting are the ellipse center coordinates of $x_{0}$ and $y_{0}$, the lengths of the minor and major axes, and the orientation of the major, or the minor, axis. The orientation of $S_{H \max }$ is determined to be the direction of the minor axis of the tted ellipse.

Figures $8(\mathrm{a})-(\mathrm{g})$ show the relative changes of the borehole shapes (black dots), and the $S_{H \max }$ orientation (solid arrows), estimated at 1-3 different depths at the 7 sites. The data coverage around the borehole axis is not always perfect, because the borehole radius was sometimes too large to measure with the laser sensor, as explained in the previous section. Data ranging, for example, from N310 to N90 in Fig. 8(a-1), from N120 to N170 and from N240 to N270 in Fig. 8(b-1), are lost. We can see various cases of the results of measurements in Fig. 8: clear ellipses are observed in the cases of Figs. 8(b-1), (d-1and d-2), (e-1), and (f-1). In the case of Figs. 8(a-1), (b-2 and b-3), and (g-1), shortwavelength perturbations overlapped on the elliptical shape are dominant. Although the reason why the data sometimes exhibit a large perturbation of short wavelengths is not clear, we think that the perturbations are not due to some error in measurement, but due to an actual deformation due to some inhomogeneity such as small fractures at each depth. On the other hand, Fig. 8(e-2) shows that the deformation is not elliptical, but almost circular without the short-wavelength perturbation. Thus, data quality seems to be affected mainly by three aspects: the rst one is the data coverage, the sec- ond is the extent of the short-wavelength perturbations, and the third is a attening parameter of the ellipse. The goodness of the least-square tting might be related to the rst and second aspects.

Among these three aspects, we chose the attening parameter of the ellipse as an indicator of the data reliability, because the attening parameter is likely to be directly related to the anisotropic stress state. The data coverage, and the short-wavelength perturbations, will be used as auxiliary indicators. Thus, we have introduced a parameter $F$ $(=(a-b) / a)$ of the nominal attening of the ellipse tted to the relative change of the borehole shape as the degree of borehole deformation, where $a$ and $b$ are the lengths of the major and minor axes, respectively. It should be noted that $a$ and $b$ are given not by the actual shape of the borehole, but by the nominal shape assuming the original borehole shape is a true circle with a diameter of $116 \mathrm{~mm}$. The parameter $F$ is given at the lower right of each gure. The larger is the value of $F$, the more reliable is the estimation. The orientation determined with a small value of $F$ is considered to be sensitive to data noise. In the case, for example, of $F<1 / 400 \%$, which means $a-b<2.5 \mu \mathrm{m}$, roughly a data error of measurement as indicated in Fig. 7, the estimation is unlikely to be reliable. The results of the $S_{H \max }$ orientations, and the value of $F$ estimated from the data, are summarized also in Table 1.

It is noted that the $S_{H \max }$ orientations estimated at two different depths are almost the same as NNW-SSE at site No. 1, while the $S_{H \max }$ orientations at different depths at sites No. 3, No. 6, and No. 7 are not uniform, respectively. It is noted that a difference of the attening parameter $F$ between the depths of $10.8 \mathrm{~m}$ and $14.35 \mathrm{~m}$, at site No. 3, might be too small to decide which orientation of $S_{H \max }$ is dominant. On the other hand, the differences of $F$ between different depths at the sites No. 6 and No. 7 are so large that we could choose dominant orientations. Results of the estimated $S_{H \max }$ orientation, at all 7 locations, are shown in Fig. 9, where white bold lines show the $S_{H \max }$ orientations. The theoretical orientations of $S_{H \max }$, due to the effect of topography, are also shown in Fig. 9 by black dotted lines. We will describe how to calculate the topography effect in the next section. The orientation is overlaid in the gure when more than one orientation result is estimated at different depths at the same location. The length of the line is proportional to the value of $F$ so that results with a large $F$ value are relatively compared. A scale of $F=1 / 100 \%$ is shown in the upper right. It is seen that the $S_{H \max }$ orientations having a large $F$ value are generally in a narrow range between NW-SE to NNW-SSE. The results of 5 other stress measurements shown in Cui et al. (2006) (open circles), and in Huang et al. (2009) (closed circles), are also drawn in Fig. 9. Their data have almost the same tendency as the results of the present experiment. Thus, almost all the stress measurements indicate that $S_{H \max }$ is in the range between NW-SE to NNW-SSE. It is worth noting here that the $S_{H \max }$ orientation is favorable for strike-slip on the Anninghe fault, while the shear stress near the Zemuhe fault is small. 
$(\mathrm{a}-1)$

No. 1

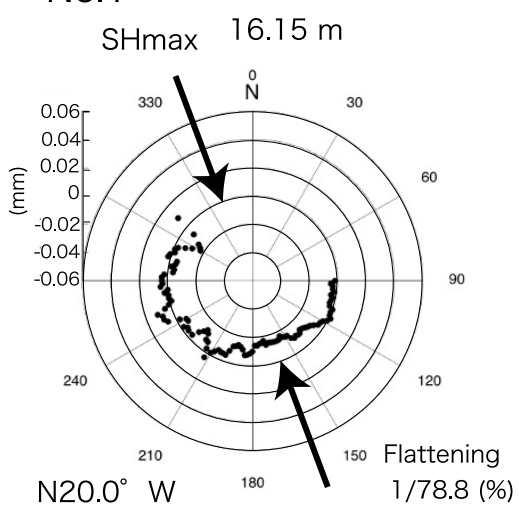

(a-2)

No. 1

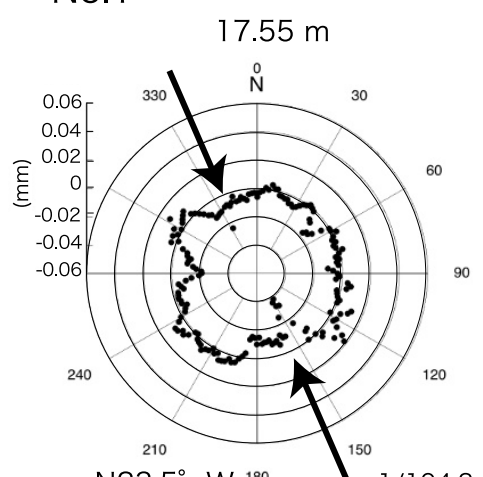

(b-1)

No.3 $10.80 \mathrm{~m}$

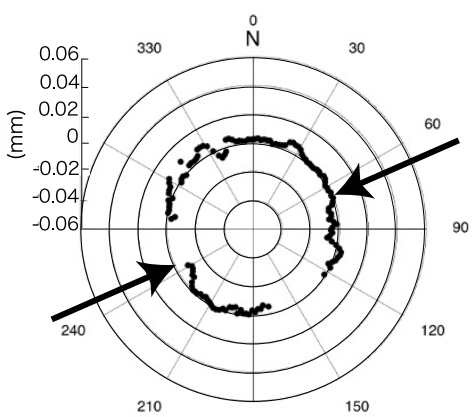

N66.3 $3^{\circ}$ E ${ }^{180} \quad 1 / 173.8(\%)$ (b-2)

No.3 $12.73 \mathrm{~m}$

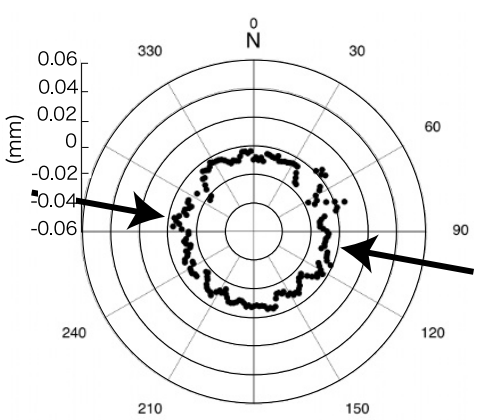

$\mathrm{N} 79.7^{\circ} \mathrm{W}^{180} \quad 1 / 602.0(\%)$

(d-1)

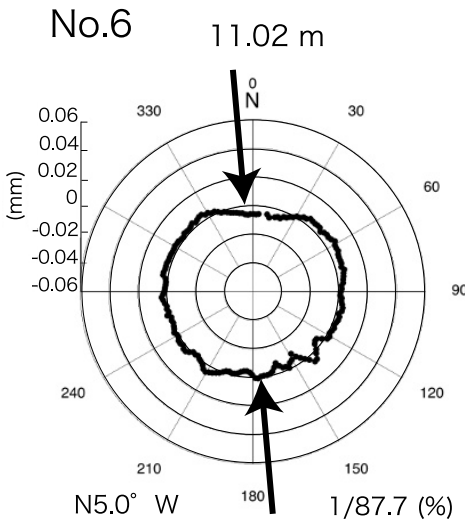

(e-2)

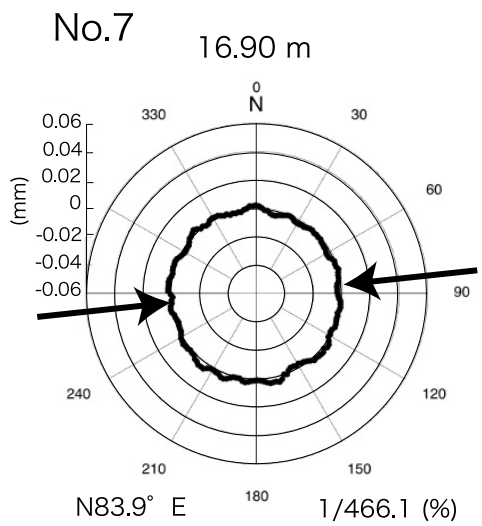

(b-3)

\section{No.3 $14.35 \mathrm{~m}$}

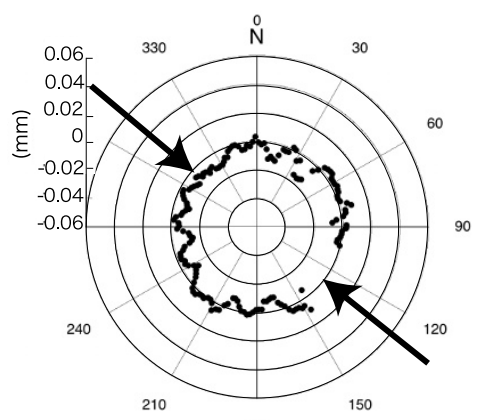

$\mathrm{N} 50.2^{\circ} \mathrm{W}^{180} \quad 1 / 205.8(\%)$ (d-2)

No.6 $11.68 \mathrm{~m}$

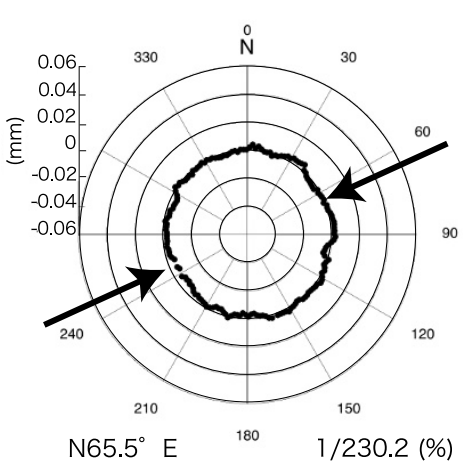

(f- 1$)$

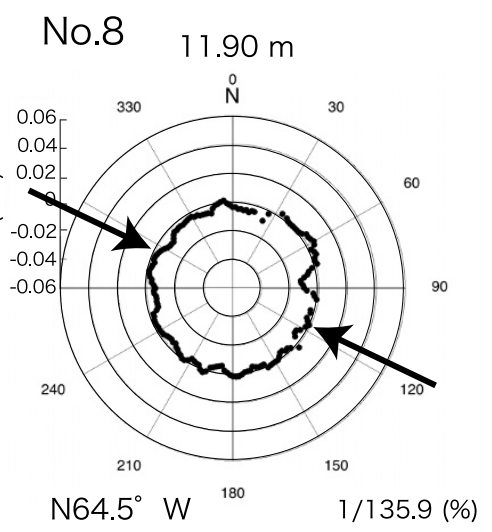

(c-1)

No.5 $11.70 \mathrm{~m}$

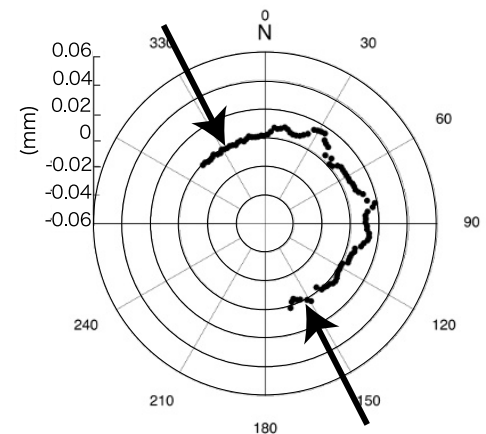

$\mathrm{N} 27.1^{\circ} \mathrm{W}$ (e-1)

No.7 $15.21 \mathrm{~m}$

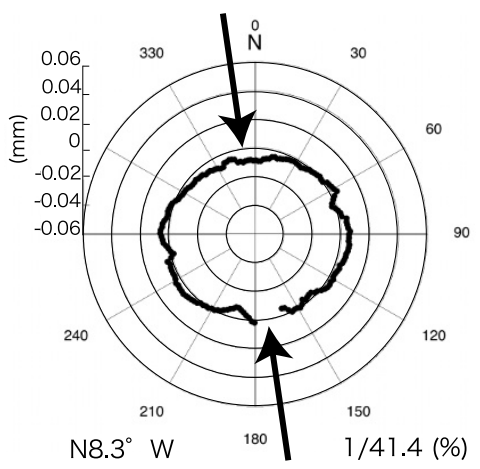

(g-1)

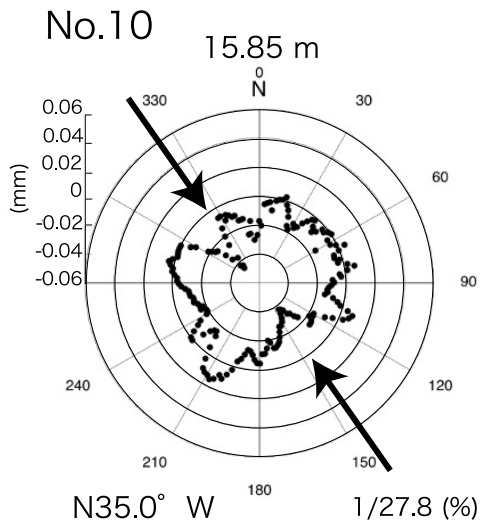

Fig. 8. Relative changes of the borehole shapes (black dots) and $S_{H \max }$ orientations (arrows) estimated from ellipse fitting at the 7 locations. 


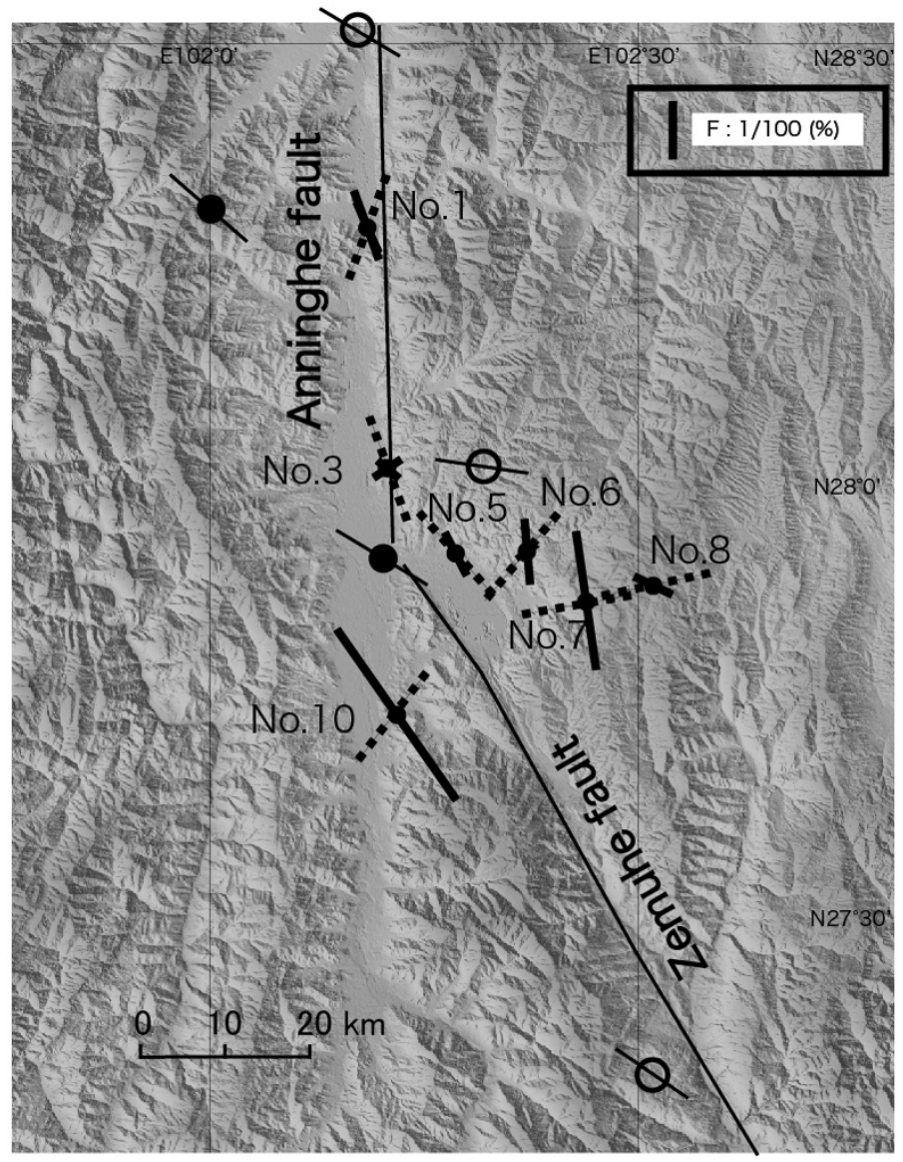

Fig. 9. Map of $S_{H \max }$ orientations. The length of the white bar is proportional to the value of the flattening parameter of the ellipse which expresses the degree of borehole deformation. The data from the other study of Cui et al. (2006) (open circles) and in Huang et al. (2009) (closed circles) are also shown. The dotted line at each site denotes a theoretical stress orientation caused by the gravitational effect of landscape topography.

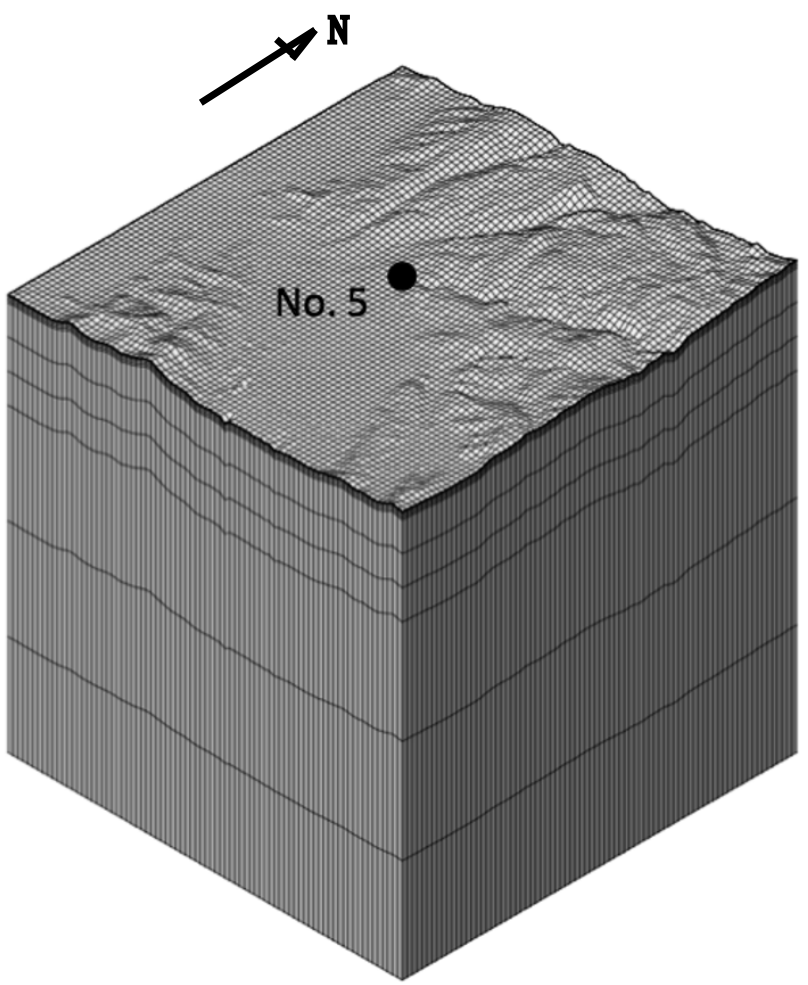

Fig. 10. An example of a finite element model at site No. 5 for calculations of the topography effect on crustal stress. 
Table 2. Physical constants applied to each element of the FEM.

\begin{tabular}{|l|c|c|c|c|}
\hline depth $(\mathrm{m})$ & $\mathrm{Vp}-1(\mathrm{~km} / \mathrm{s})$ & $\mathrm{Vp}-2(\mathrm{~km} / \mathrm{s})$ & Poisson's ratio & $\rho\left(\mathrm{g} / \mathrm{cm}^{3}\right)$ \\
\hline $0-100$ & 3.8 & 3.8 & 0.25 & 2.7 \\
\hline $100-1000$ & 5.2 & 4.5 & 0.25 & 2.7 \\
\hline $1000-5000$ & 5.75 & 5 & 0.25 & 2.7 \\
\hline $5000-10000$ & 5.88 & 6 & 0.25 & 2.7 \\
\hline $1000-20000$ & 5.95 & 6.5 & 0.25 & 2.7 \\
\hline
\end{tabular}

Table 3. Stresses and the azimuths of the $S_{H \max }$ at a depth of $17.5 \mathrm{~m}$ calculated from the FEM model.

\begin{tabular}{|c|c|c|c|c|c|c|c|c|c|}
\hline \multirow[b]{2}{*}{ Site } & \multirow[b]{2}{*}{ Model } & \multicolumn{4}{|c|}{ Model Vp-1 } & \multicolumn{4}{|c|}{ Model Vp-2 } \\
\hline & & $\begin{array}{c}S_{z z} \\
(\mathrm{kPa})\end{array}$ & $\begin{array}{c}S_{H \max }{ }^{*} \\
(\mathrm{kPa})\end{array}$ & $\begin{array}{c}S_{H \min }{ }^{*} \\
(\mathrm{kPa})\end{array}$ & $\Phi$ & $\begin{array}{c}S_{z z} \\
(\mathrm{kPa})\end{array}$ & $\begin{array}{c}S_{H \max }{ }^{*} \\
(\mathrm{kPa})\end{array}$ & $\begin{array}{c}S_{H \min } * \\
(\mathrm{kPa})\end{array}$ & $\Phi$ \\
\hline \multirow{2}{*}{ No. 1} & Size10 & 436.3 & -61.0 & -1325.3 & 2.6 & 434.8 & -122.0 & -1251.5 & 1.9 \\
\hline & Size20 & 429.1 & -211.4 & -2096.1 & 19.3 & 367.3 & -539.3 & -3142.6 & 20.6 \\
\hline \multirow{2}{*}{ No. 3} & Size10 & 529.8 & 528.2 & 371.6 & 170.9 & 518.2 & 467.6 & 229.2 & 171.6 \\
\hline & Size20 & 511.4 & 577.6 & 245.4 & 155.7 & 508.3 & 561.6 & -189.4 & 162.7 \\
\hline \multirow{2}{*}{ No. 5} & Size10 & 467.8 & -44.8 & -427.5 & 144.2 & 467.9 & -11.4 & -389.0 & 142.0 \\
\hline & Size20 & 474.6 & -98.8 & -773.9 & 135.1 & 466.1 & -147.2 & -1196.4 & 131.4 \\
\hline \multirow{2}{*}{ No. 6} & Size10 & 536.4 & 1116.3 & -972.7 & 39.5 & 531.1 & 1140.3 & -870.3 & 42.0 \\
\hline & Size20 & 481.9 & 952.9 & -1004.3 & 39.7 & 470.0 & 1028.0 & -1394.4 & 42.3 \\
\hline \multirow{2}{*}{ No. 7} & Size10 & 613.5 & 1681.1 & 652.4 & 67.5 & 601.8 & 1640.7 & 567.2 & 71.5 \\
\hline & Size20 & 587.4 & 2035.7 & 696.3 & 86.2 & 594.2 & 2393.3 & 507.0 & 89.0 \\
\hline \multirow{2}{*}{ No. 8} & Size10 & 556.7 & 785.1 & 138.2 & 58.5 & 552.5 & 817.0 & 203.3 & 67.9 \\
\hline & Size20 & 506.7 & 1709.9 & 585.1 & 85.7 & 512.1 & 2718.5 & 748.7 & 93.8 \\
\hline \multirow{2}{*}{ No. 10} & Size10 & 446.8 & 324.4 & -1217.3 & 41.6 & 453.9 & 310.5 & -961.4 & 42.7 \\
\hline & Size20 & 388.1 & 156.5 & -1953.4 & 33.3 & 352.7 & -128.0 & -2659.1 & 32.6 \\
\hline
\end{tabular}

Positive: compression, $\phi: S_{H \max }$ orientation (degree clockwise from north).

\section{Effect of Landscape Topography on the Stress State at Shallow Depths}

The topography effect, due to gravity, should be evaluated on the stress states, particularly when the stress measurements are conducted at shallow depths (e.g. Liu and Zoback, 1992; Nakajima, 1982). We therefore conducted 3-D nite-element modeling to take into account the actual topography around the measuring site, using a digital elevation model (DEM). A commercial software code, namely, SoilPlus (CTC co.), of a nite element method (FEM) was used to solve the problem. The DEM of about a 30-m-grid mesh around the site was downloaded from the ASTER GDEM web site. The average slope between the highest site, No. 8 , and site No. 5 , is about $5^{\circ}$. The boundary conditions of the FEM models are as follows: displacements across the four lateral faces, and the bottom one, are xed, and other displacement components are free. Since the depths we are concerned with were in the range 10$20 \mathrm{~m}$, grid sizes of the shallow parts have to be less than $5 \mathrm{~m}$ in the vertical direction. Thus, we divided the model in the vertical direction into 5 layers: in the ranges $0-25 \mathrm{~m}$, 25-75 m, 75-375 m, 375-4875 m, and 4875-10000 m, respectively. The rst layer is then divided evenly into 5 grids in the vertical direction, and the other layers are evenly divided into 3 grids, respectively. The model size is $10 \mathrm{~km} \times 10 \mathrm{~km} \times 10 \mathrm{~km}$, which is determined from the general size of the topographies. We also performed the calculation for a model size of $20 \mathrm{~km} \times 20 \mathrm{~km} \times 20 \mathrm{~km}$ in order to check the effect of the model size on the results. Figure 10 shows an example of the FEM model for site No. 5. The horizontal grid sizes for the $10 \mathrm{~km}$ and $20 \mathrm{~km}$ models are $125 \mathrm{~m}$ and $250 \mathrm{~m}$, respectively. Physical constants such as the $P$-wave velocity, Poisson's ratio, and the density, applied to each element are summarized in Table 2, where the Poisson's ratio and density are assumed to be constant. In the present study, we have constructed two $P$-wave velocity models, namely Models Vp-1 and Vp-2, taking into consideration the measured $P$-wave velocities of the boring core samples and a $P$-wave velocity model used for earthquake locations (Yang, Z.-X. et al., 2004) in order to check the effect of the difference of the velocity models. Thus, we calculate four cases with respect to the two $P$-wave velocity models and to the two model sizes, namely, Size 10 and Size 20, respectively. The measuring sites are always put at the center of the models.

Results for the four cases are shown in Table 3 for each site where the stress orientation data are obtained. All the results of stresses and the azimuths of $S_{H \max }$ are calculated at a depth of $17.5 \mathrm{~m}$ from the surface. It is noted that the stress elds are tensional at sites No. 1 and No. 5 for all four models. $S_{H \max }$ is regarded as a principal stress with a smaller absolute value than another principal stress in the tensional stress case. The results show noticeable variation, according to site location. If the topography were at, $S_{H \max }$ and the other horizontal principal stress, $S_{H \text { min }}$, were always $(v /(1-v)) S_{z z}$, where $v$ is Poisson's ratio and $(v /(1-v))=1 / 3$ when $v=0.25$ (e.g. Savage et al., 1992). On the other hand, we can see a clear topography effect 
from the results, sometimes showing $S_{H \max }$ larger than $S_{z z}$, or the tensional stresses.

The results of the computed topography effect for the four models at each site are generally within a narrow range of $10^{\circ}-20^{\circ}$. A mean azimuth at each site is plotted with a dotted line in Fig. 9, with the result of actual measurement. We can see a general tendency that the calculated $S_{H \max }$ azimuths, due to the effect of topography, are parallel to a valley at the foot of a mountain, and the azimuth is parallel to the slope of the mountain in the middle of the mountain. We can also see that the measured results are not likely to coincide with the calculated ones. Thus, we conclude that the topography effects are negligibly small in the present experiment.

\section{Discussion}

The measured data show spatial variations to some extent, while the orientations of $S_{H \max }$ are in the range between NW-SE to NNW-SSE. We try here to compare the observed $S_{H \max }$ orientations with theoretical stress elds calculated with the Coulomb software, regarding the different stress states on both faults. Parameters mainly examined for the calculation are the orientation of a far eld stress and the extent of the stress relief on the fault. We examined the orientation of far eld stress in a range between $\mathrm{N} 45^{\circ} \mathrm{W}$ and $\mathrm{N} 60^{\circ} \mathrm{W}$, because the stress orientations outside this range are too steep relative to the Zemuhe fault, or too large relative to the Anninghe fault, thereby exceeding the lock-up angle for the case of a frictional coef cient of 0.6 (Sibson and Xie, 1998). After several calculations with dif-

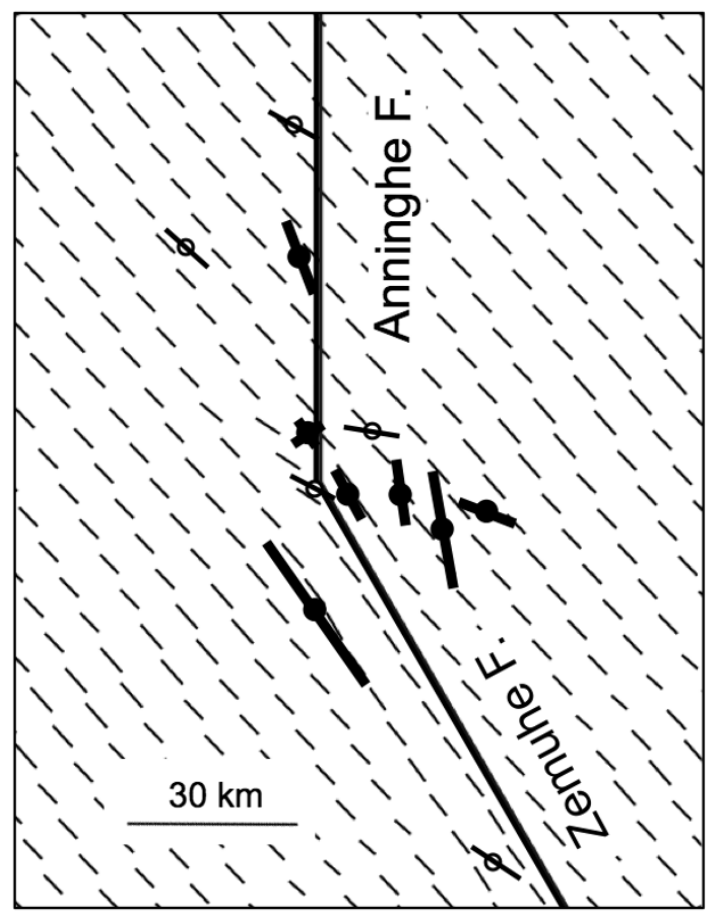

Fig. 11. Comparison of the observed stress orientation with the theoretical one, in the cases that the stress reliefs on the Anninghe and the Zemuhe faults is $0 \%$ and $100 \%$, respectively. An orientation of a far eld tectonic stress is $\mathrm{N} 45^{\circ} \mathrm{W}$. The bold lines with closed circles and thin lines denote the observed and calculated data, respectively. Lines with open circles denote the data of Cui et al. (2006) and Huang et al. (2009). ferent parameters, we were not able to determine which parameters were the best, because the differences between the calculated results, for the various parameters, were small compared with uctuations of the actual data. We therefore adopt the parameters used in Fig. 3(a) as being representative. Figure 11 shows a comparison of the calculation of Fig. 3(a) with the data of the present experiments, and with the other data of Cui et al. (2006) and Huang et al. (2009). It seems that the observed orientations at sites No. 6 and No. 7 are dif cult to be tted by the calculations for all the parameters, because the measured stress directions are in the sense of a right-lateral slip on the Zemuhe fault. Thus, these uctuations are likely caused by other nonuniformities than the present simple model of different stress states on the faults.

More sophisticated theoretical calculations concerning, for example, the nonuniform stress on the fault might be necessary in order to evaluate quantitatively the stress eld along the fault zone. However, the causes of error in the data is not necessarily clari ed, at present, because stress orientations are affected by many unknown nonuniformities such as small fractures, and elastic constants in and around the borehole. Therefore, more data are necessary to perform a more sophisticated analysis. It might be dif cult to conclude that the measured stress pattern is related to the past activity of each fault. The present experiment, so far, indicates that the orientation of $S_{H \text { max }}$ of the tectonic stress is in the range $\mathrm{N} 45^{\circ} \mathrm{W}-\mathrm{N} 60^{\circ} \mathrm{W}$ and that the orientations of $S_{H \max }$ are almost parallel to the fault strike of the Zemuhe fault, and favorable to slip of the Anninghe fault, respectively.

\section{Summary}

We measured the stress orientations at 7 sites around the Anninghe-Zemuhe fault zone to test the detectability of spatial variations in the stress state caused by the difference of the stress state on the two faults, using a newly-developed method. The results show that the observed orientation is roughly NW-SE, which is consistent with the tectonic stress eld estimated by other methods of stress measurements, and of earthquake focal mechanism solutions. This indicates that the new method gives promising data. Further, the shear stress observed on the Zemuhe fault seems to be small compared with the tectonic stress. The present results indicate that the stress acting on the Anninghe fault is favorable to slip on the fault, while the stress acting on the Zemuhe fault is not.

Acknowledgments. This work was supported by the Ministry of Science and Technology of the People's Republic of China under contract no. 2006DFA21660. DEM data around the studied area were downloaded from http://www.ersdac.or.jp/GDEM/J/1.htm. We appreciate Dr. K. Omura and Dr. Y. Yabe for their constructive comments and suggestions on the revisions of the manuscript.

\section{References}

Aki, K., Earthquake mechanism, Tectonophysics, 13, 423-446, 1972. Cheng, W.-Z., R. Xiang, and Y.-J. Zhang, Types of focal mechanism solutions and parameter consistency of the sub-blocks in Sichuan and Yunnan Provinces, Acta Seismol. Sinica, 19, 605-619, 2006.

Cui, X.-F., F.-R. Xie, and H.-Y. Zhang, Recent tectonic stress eld zoning in Sichuan-Yunnan region and its dynamic interest, Acta Seismol. 
Sinica, 19, 485-496, 2006.

Hardebeck, J. L. and E. Hauksson, Crustal stress eld in southern California and its implications for fault mechanics, J. Geophys. Res., 106, 21,859-21,882, 2001.

Huang, R., Z. Wang, S. Pei, and Y. Wang, Crustal ductile ow and its contribution to tectonic stress in Southwest China, Tectonophysics, $\mathbf{4 7 3}$, 476-489, 2009.

Kiguchi, T. and Y. Kuwahara, Stress orientation measurements around the Kego fault: Application of a new technique of a borehole deformation measurement, Ann. Rep. Active Fault Paleoearthq. Res., 6, 153-161, 2006 (in Japanese with English abstract).

Kiguchi, T., Y. Kuwahara, N. Sato, and T. Yokoyama, Development of a new tool of laser scanner for borehole deformation to estimate stress orientation at shallow depth, Bull. Geol. Surv. Jpn., 61, 337-350, 2010 (in Japanese with English abstract and gure captions).

Knopoff, L., Energy release in earthquakes, Geophys. J., 1, 44-52, 1958.

Kubo, A. and E. Fukuyama, Stress elds and fault reactivation angles of the 2000 western Tottori aftershocks and the 2001 northern Hyogo swarm in southwest Japan, Tectonophysics, 378, 223-239, 2004.

Kuwahara, Y. and T. Kiguchi, A new method for estimation of in-situ crustal stress orientations by measuring creep deformation of a borehole, Inspection Engineering (Kensa-Gijutsu), 11, 28-33, 2006 (in Japanese).

Liu, L. and M. D. Zoback, The effect of topography on the state of stress in the crust: Application to the site of the Cajon Pass scienti c drilling project, J. Geophys. Res., 97, 5095-5108, 1992.

Nakajima, T., Topography effects on crustal stress eld (I), Zisin 2 (J. Seismol. Soc. Jpn.), 35, 591-606, 1982.

Plumb, R., T. Engelder, and M. Sbar, Near-surface in situ stress 2. Comparison with stress directions inferred from earthquakes, joints, and topography near Blue Mountain Lake, New York, J. Geophys. Res., 89, 9333-9349, 1984.

Sato, N., Y. Kuwahara, and T. Kiguchi, On an estimation of shallow stress eld, Program abstract of Japan Seismological Society 2004 Fall Meeting, P106, 2004.

Savage, W. Z., H. S. Swalps, and B. Amadei, On the state of stress in the near-surface of the Earth's crust, Pure Appl. Geophys., 138, 207-228, 1992.

Sbar, M. L., R. M. Richardson, C. Flaccus, and T. Engelder, Near-surface in situ stress 1. Strain relaxation measurements along the San Andreas fault in southern California, J. Geophys. Res., 89, 9323-9332, 1984.

Sibson, R. H. and G. Xie, Dip range for intracontinental reverse fault ruptures: truth not stranger than friction?, Bull. Seismol. Soc. Am., 88, 1014-1022, 1998.

Toda, S., R. S. Stein, P. A. Reasenberg, and J. H. Dieterich, Stress transferred by the Mw=6.5 Kobe, Japan, shock: Effect on aftershocks and future earthquake probabilities, J. Geophys. Res., 103, 24543-24565, 1998.

Wen, X., J. Jia, M. Pan, H. Liang, and Y. Cai, Recent slip rates, earthquake recurrence intervals and strong seismic hazards on the northwestern segment of the Xianshuihe fault zone, Earthquake Research in China, 2, 431-451, 1988.

Wen, X., J. Fun, G. Yi, Y. Deng, and F. Jong, A seismic gap on the Anninghe fault in western Sichuan, China, Sci. China Ser. D-Earth Sci., 51, 1375-1387, 2008.

Yamashita, F., E. Fukuyama, and K. Omura, Estimation of fault strength: reconstruction of stress before the 1995 Kobe earthquake, Science, 306, 261-263, 2004.

Yang, A. X., F. Waldhauser, Y. T. Chen, and P. G. Richards, DoubleDifference relocation of earthquakes in central-western China, 19921999, J. Seismol., 9, 241-264, 2005.

Yang, S.-M., Q. Wang, and X. You, Numerical analysis of contemporary horizontal tectonic deformation elds in China from GPS data, Acta Seismol. Sinica, 18, 135-146, 2005.

Yang, Z.-X., X.-W. Yu, Y.-J. Zeng, Y.-T. Chen, X.-X. Ni, and W. Chan, Earthquake relocation and 3-dimensional crustal structure of P-wave velocity in central-western China, Acta Seismol. Sinica, 17, 20-30, 2004.

Y. Kuwahara (e-mail: y-kuwahara@aist.go.jp), T. Kiguchi, X. Lei, S. Ma, X. Wen, and S. Chen 